\title{
Convergência brasileira aos padrões internacionais de contabilidade pública vis-à-vis as estratégias top-dow e bottom-up
}

Janyluce Rezende Gama

Universidade Federal do Espirito Santo

Claudio Gottschalg Duque

Universidade de Brasilia

José Elias Feres de Almeida

Universidade Federal do Espirito Santo

O Brasil está em processo de convergência de sua contabilidade pública em relação aos padrões internacionais desenvolvidos pela Federação Internacional dos Contadores (Ifac). A implementação de sistemas de informação contábil é geralmente realizada por meio das abordagens top-down ou bottomup. Assim, este estudo tem por objetivos: 1) identificar a abordagem adotada pelo governo federal brasileiro; 2) descrever o modelo de implementação do sistema de informação contábil público no Brasil; e 3) mapear o fluxo de informações e atores envolvidos no processo de convergência. A abordagem qualitativa foi adotada utilizando a pesquisa documental e análise de conteúdo de documentos disponíveis para operacionalizar a pesquisa. Foi identificado que o Brasil utiliza a abordagem middleup-down, que favorece a interação entre múltiplos atores no processo, diferentemente da abordagem top-down, que segue o modelo internacional divulgado.

Palavras-chave: sistema de informação; Federação Internacional dos Contadores; contabilidade pública internacional; abordagem top-down; abordagem bottom-up.

Convergencia brasileña con los estándares internacionales de contabilidad pública vis-à-vis las estrategias top-down y bottom-up

Brasil pasa por un proceso de convergencia de su contabilidad pública con relación a los estándares internacionales desarrollados por la Federación Internacional de Contadores (Ifac). La implementación de sistemas de información contable es realizada generalmente por medio de los abordajes top-down o bottom-up. Así, este estudio tiene como objetivos: 1) identificar el abordaje adoptado por el gobierno federal brasileño; 2) describir el modelo de implementación del sistema de información contable pública en Brasil; y 3) mapear el flujo de informaciones y los actores involucrados en el proceso de

Artigo recebido em 29 dez. 2012 e aceito em 11 nov. 2013.

Rev. Adm. Pública - Rio de Janeiro 48(1):183-206, jan./fev. 2014 
convergencia. El abordaje cualitativo fue adoptado utilizando la investigación documental y el análisis de contenido de documentos disponibles para poner en operación la investigación. Se identificó que Brasil utiliza el abordaje middle-up-down, que favorece la interacción entre múltiples actores en el proceso, diferentemente del abordaje top-down, que sigue el modelo internacional divulgado.

Palabras clave: sistema de información; Federación Internacional de Contadores; contabilidad pública internacional; abordaje top-down; abordaje bottom-up.

Brazilian convergence with the international standards of public accounting vis-à-vis the topdown and bottom-up strategies

Brazil is undergoing a convergence process of its public accounting with regard to the international standards developed by the International Federation of Accountants (Ifac). The implementation of accounting information systems is usually conducted by means of the top-down or bottom-up approaches. Thus, this study aims to: 1) identify the approach adopted by the Brazilian federal government; 2) describe the implementation model of the public accounting information system in Brazil; and 3) map the information flow and the actors involved in the convergence process. A qualitative approach was adopted using documentary survey and content analysis of available documents to put the research into operation. We identified that Brazil uses the middle-up-down approach, which favors interaction between multiple actors in the process, unlike the top-down approach, which follows the international model disclosed.

KEYWORDs: information system; International Federation of Accountants; international public accounting; top-down approach; bottom-up approach.

\section{Introdução}

O desenvolvimento de sistemas de informação envolve diversos campos de conhecimento. Vários são os campos do conhecimento envolvidos na teoria dos sistemas de informação, entre eles sociologia, economia, administração, educação, comunicação, engenharias, psicologia e ciência da computação (Zins, 2007).

Dessa maneira, além de uma compreensão básica de sistemas e de elementos humanos comportamentais, Hirschheim (1992) afirma que "a epistemologia de sistemas de informação baseia-se fortemente nas ciências sociais, porque os sistemas de informação são, fundamentalmente, sociais ao invés de sistemas técnicos", proporcionando maior integração entre os atores envolvidos em processos de implementação de sistemas de informação.

A contabilidade aplicada ao setor público, como área específica da ciência social aplicada, é organizada na forma de sistema de informação, cujos subsistemas orçamentário, patrimonial, custos e de compensação, conquanto possam oferecer produtos diferentes em razão da respectiva especificidade, convergem para o produto final, que é a informação sobre o patrimônio público (CFC, 2008b). Esse sistema de informações, chamado de contabilidade pública, passa neste momento por um processo de convergência ao modelo internacional desenvolvido pela International Federation of Accountants (Ifac), por meio do International 
Public Sector Accounting Standards Board (Ipsasb), considerado arcabouço normativo de alta qualidade (Chan, 2010). Essa nova estrutura tem como objetivo aprimorar a transparência das finanças públicas em todos os seus desdobramentos, procurando evitar práticas de corrupção ou de gestão inadequada dos recursos públicos (Nascimento, 2007).

No Brasil, o processo de convergência foi iniciado com o apoio do Conselho Federal de Contabilidade (CFC), como Conselho Profissional de Classe, e da Secretaria do Tesouro Nacional (STN), como representante do governo (Herbest, 2010). Esse modelo internacional foi adotado pelo governo federal brasileiro de forma obrigatória para todos os demais entes públicos da federação, ou seja, não apenas a União, mas também estados e municípios.

Para implementar um novo sistema de informação é necessário fazer uma escolha da abordagem mais adequada para reduzir incertezas durante o processo. Usualmente o governo federal opta pela abordagem top-down, em que o processo de desenvolvimento da arquitetura de informação é realizado com base no entendimento do contexto, das condições do ambiente, do conteúdo, dos tipos de informações que precisam ser geradas e das necessidades dos usuários. Todavia, outras duas abordagens podem ser utilizadas, a bottom-up e a middle-updown. Na abordagem bottom-up, o processo de desenvolvimento de um sistema de informação é realizado com base no entendimento das ferramentas utilizadas pelos usuários por meio de diagnóstico, mapeando fluxos de processos e informações, para alavancar o conteúdo a ser utilizado pelo sistema, incluindo, por exemplo, pesquisas e índices (Hagedorn, 2000), enquanto na abordagem middle-up-down os conceitos e os meios para implementação do sistema são elaborados pelos atores intermediários responsáveis pelo processo (Nonaka, 1988).

A literatura traz alguns pontos relevantes no processo de implementação de sistemas de informação que precisam ser observados pelos responsáveis, de acordo com Nascimento (2007) e Zeff (2007), são eles: i) Não participação dos atores que deveriam estar envolvidos no processo; ii) Falha no compartilhamento das informações entre os atores; iii) Falta de incentivos aos atores para contribuir com o processo; iv) Problemas de interpretação, terminologias e linguagem; v) Falta de apoio político, mão de obra especializada e tecnologia; e vi) mudança na cultura organizacional (Alvarenga Neto, Barbosa e Pereira, 2007).

Nesse contexto, o governo federal criou o Grupo Técnico de Padronização de Procedimentos Contábeis (GTCON) para mediar a convergência perante vários atores, inclusive os apoiadores iniciais (CFC e STN). Ao designar a análise do contexto e conceitos do sistema de informação aos atores, o governo federal se afasta da figura de ator principal do processo, condição esta que pode acarretar problemas e dificuldades no futuro, caso o modelo contábil da Ifac, que é a intenção da convergência, não for implementado em sua totalidade ou sofrer alterações durante o processo.

Pelo exposto, pretende-se, a partir do contexto do cenário brasileiro apresentado, investigar o seguinte problema de pesquisa: Como está sendo implementado o modelo do novo sistema de informação contábil no setor público?

Dessa maneira, este estudo tem como objetivo principal identificar a abordagem adotada pelo governo federal e, como objetivos secundários, descrever o modelo de implementação do novo sistema contábil da administração pública, além de mapear o fluxo de informações 
e os atores envolvidos nesse processo. Com o levantamento e a apresentação do modelo adotado pelo governo federal, essa pesquisa pretende incentivar a classe contábil a fazer parte desse processo participando das estratégias de formulação e implementação de políticas contábeis junto aos órgãos reguladores.

Na perspectiva metodológica, este estudo possui abordagem qualitativa conforme Godoy (1995a) e Huff (2009). Essa abordagem permite conhecer mais adequadamente o fenômeno observado, mesmo de maneira exploratória. Para identificar a abordagem e o modelo de implementação do sistema de informação contábil adotado pelo governo federal, foi utilizada a pesquisa documental como método para descrever e levantar o fluxo da informação com base em leis, decretos, portarias, atas, normas internacionais emitidas pela Ifac, e no arcabouço normativo emitido pelo Conselho Federal de Contabilidade (CFC) e pela Secretaria do Tesouro Nacional (STN), além do regimento interno, calendários das reuniões e lista de participantes das reuniões do GTCON.

A partir da análise qualitativa realizada, foi possível identificar que a abordagem middle-up-down é a utilizada na prática, diferentemente da abordagem top-down tradicionalmente aplicada pelo governo. De acordo com os objetivos secundários, foi identificado que o modelo adotado destoa do proposto pelo governo federal conforme modelo esquematizado pela STN. Além disso, esse modelo mapeado, pela análise qualitativa, pode gerar conflitos e morosidade no processo, podendo ocorrer possíveis interferências por disputa de poder no processo.

Este artigo está dividido da seguinte maneira após a introdução: a seção 2 apresenta o referencial teórico; já a seção 3 apresenta os procedimentos metodológicos; a seção 4 discute a abordagem identificada e a análise do modelo; por fim, as considerações finais, limitações do estudo e sugestões para futuras pesquisas são apresentadas no tópico 5.

\section{Referencial teórico}

\subsection{Sistemas de informação e sistemas de informação contábil}

O sistema de informação (SI) pode ser analisado de três maneiras diferentes: primeiro, como um sistema técnico implementando tecnologia da informação e telecomunicações; segundo, como um sistema social, como uma organização em conexão com suas necessidades de informação; e terceiro, como um sistema conceitual, ou seja, uma abstração de qualquer um dos anteriores (Ifip, 1998).

O foco de atuação da maioria dos estudos em SI relaciona-se com questões da análise organizacional, ampliando-se cada vez mais para incluir temas abrangentes (Rodrigues Filho e Ludmer, 2005). Contudo, pode-se afirmar que há ligação entre sistema de informação e tecnologia da informação. Essa vinculação se faz evidente quando se considera que o sistema de informação envolve pessoas, tecnologias, procedimentos e a adoção de métodos (Amorim e Tomaél, 2011). 
Segundo Capurro e Hjorland (2007:193),

Quando representamos os dados em nossos sistemas de informação, o fazemos a fim de dar suporte a certas atividades humanas. Não deveríamos simplesmente considerar nossas representações como objetivas, porque isto implica que nunca especificamos completamente as suposições teóricas, sociais e históricas com base nas quais agimos. Todos os tipos de sistemas de informação têm políticas e objetivos mais ou menos explícitos. O que consideramos como informação deveria também ser um reflexo da função social do sistema de informação.

No campo das ciências sociais aplicadas encontra-se a contabilidade. Nas ciências contábeis, o sistema de informação contábil representa a estrutura de informação sobre identificação, mensuração, avaliação, registro, controle e evidenciação dos atos e dos fatos da gestão do patrimônio público, com o objetivo de orientar e suprir o processo de decisão, a prestação de contas e a instrumentalização do controle social (CFC, 2008b).

No setor público, o sistema de informação contábil está estruturado em subsistemas de informação com funções bem definidas, sendo eles: orçamentário, patrimonial, custos e compensação. Em 2009 o subsistema financeiro foi excluído por força da resolução CFC no 1.268/2909, porém a informação financeira passou a ser controlada no subsistema patrimonial.

Na administração pública, a contabilidade governamental é um importante instrumento de apoio às políticas públicas. Sistemas de informações contábeis podem conduzir às melhorias na gestão financeira governamental. Porém, a contabilidade governamental em si não é uma política pública, mas contribui para o desenvolvimento socioeconômico, por meio do seu efeito sobre a gestão e accountability financeira pública. No entanto, a contribuição do sistema contábil é necessariamente indireta e de longo prazo (Chan, 2010).

A função de cada subsistema é definida da seguinte forma: o subsistema orçamentário registra, processa e evidencia os atos e os fatos relacionados ao planejamento e à execução orçamentária; o subsistema orçamentário patrimonial registra, processa e evidencia os fatos financeiros e não financeiros relacionados com as variações qualitativas e quantitativas do patrimônio público; o subsistema orçamentário de custos (criado em 2009) registra, processa e evidencia os custos dos bens e serviços, produzidos e ofertados à sociedade pela entidade pública; e o subsistema orçamentário de compensação registra, processa e evidencia os atos de gestão cujos efeitos possam produzir modificações no patrimônio da entidade do setor público, bem como aqueles com funções específicas de controle (CFC, 2009).

A representação do sistema de informação da contabilidade aplicada ao setor público conforme o Conselho Federal de Contabilidade está apresentada na figura 1.

Esses subsistemas contábeis devem ser integrados entre si e a outros subsistemas de informação de modo a subsidiar a administração pública sobre o desempenho da unidade contábil no cumprimento da sua missão; a avaliação dos resultados obtidos na execução dos programas de trabalho com relação à economicidade, à eficiência, à eficácia e à efetividade; a avaliação das metas estabelecidas pelo planejamento; e a avaliação dos riscos e das contingências (CFC, 2008b). 
Figura 1

Representação do sistema de informação contábil no setor público

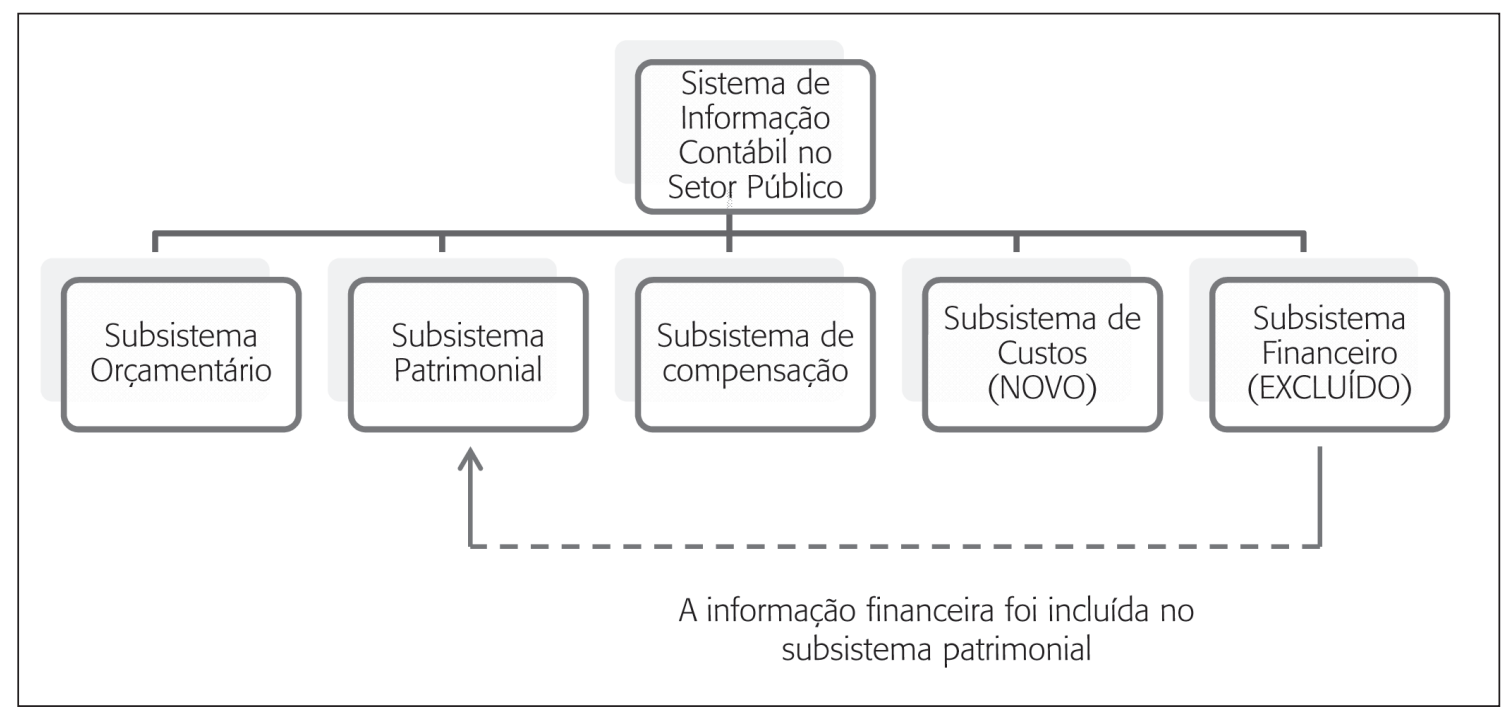

Fonte: CFC (2009).

\subsection{Abordagens top-down, bottom-up e middle-up-down no desenvolvimento dos sistemas de informação contábil na administração pública}

O estudo das abordagens utilizadas na implementação de sistemas de informações, de sistemas de gestão (Ferreira e Otley, 2009) ou de políticas públicas (Oliveira, 2006) emprega, geralmente, duas abordagens de implementação de sistemas para análise do contexto e do processo, a top-down e a bottom-up. No entanto, ambas as abordagens podem ser conflituosas dependendo da realidade investigada e do ambiente analisado, fato que culminou no equilíbrio entre as duas abordagens, surgindo a middle-up-down.

A abordagem top-down segue o modelo hierárquico clássico da pirâmide organizacional, acontecendo de cima para baixo. Já na abordagem bottom-up o conhecimento é formado pela base e a organização tem um formato mais plano, passando a ter poucos níveis hierárquicos entre o topo e a linha de frente (Pereira, 2003).

Nonaka (1988) explica que a abordagem top-down começa com o decisor central e com uma política autoritária declarada prossegue para baixo por meio da estrutura hierárquica administrativa para examinar em que extensão os objetivos legalmente foram alcançados e os procedimentos seguidos. Já a abordagem bottom-up se inicia com uma análise dos diversos atores que interagem no nível operacional e trabalha para trás para mapear os resultados e os impactos da política em termos das estratégias adotadas pelos atores em resposta à escolha particular da política. 
As abordagens top-down e bottom-up se diferenciam quanto ao foco de análise. A primeira centra-se nas normas e nos planos, desconsiderando a influência dos implementadores, já a segunda centra-se nos atores executores e suas ações. As críticas à abordagem top-down baseiam-se na constatação de que dificilmente se é capaz de elaborar normas que possam prever as condições, dinâmicas e comportamentos de uma cadeia de atores diversos e interdependentes. Já a abordagem bottom-up questiona o suposto da influência decisiva dos formuladores sobre o processo de implementação, e considera que a implementação é um processo disperso e descentralizado, reconhecendo somente o papel importante dos implementadores (Lima e D’ascenzi, 2012).

Dessa forma, na visão de Nonaka e Takeuchi (1997), nenhum dos dois modelos é adequado no processo de criação do conhecimento. Na abordagem top-down os gerentes de nível médio processam muita informação, mas raramente participam do processo de criação do conhecimento. Já na abordagem bottom-up o criador do conhecimento é certamente um indivíduo de mentalidade empreendedora da base da organização, enquanto gerentes de nível médio desempenham papel mínimo.

Segundo Brito (2008), há outra abordagem além da bottom-up e da top-down, denominada middle-up-down, em que os conceitos são construídos pelas próprias equipes de trabalho. Essa última abordagem é definida por Escrivão, Nagano e Escrivão Filho (2011) como conceito criado do meio para cima e para baixo. Nesse caso, a gerência de nível médio resolve a contradição entre o que a cúpula espera criar e o que realmente existe no mundo real (visão dos atores que atuarão no processo).

No modelo middle-up-down os gerentes de primeira linha (ou altos executivos) articulam a visão para a organização, enquanto os funcionários no operacional examinam a realidade. A defasagem entre a visão ou o sonho e a realidade é abrandada pelos gerentes de nível médio, que atuam como mediadores entre os dois, criando conceitos de produtos intermediários. Ao fazê-lo, eles resumem o conhecimento tácito da alta gerência e dos funcionários operacionais tornando-o explícito e incorporando-o a novos projetos (Silva, Ribeiro e Rodrigues, 2004). Oliveira (2006) considera essa abordagem útil na análise de políticas públicas, ainda mais durante o processo de implementação.

Nonaka (1988), analisando essas três abordagens numa montadora de veículos japonesa, sintetiza que a abordagem top-down é essencialmente dedutiva, enquanto a bottom-up é essencialmente indutiva. Na perspectiva desse autor, a abordagem middle-up-down pode incorporar os pontos fortes da gestão dedutiva e indutiva.

Porém, o modelo funcional dos sistemas de informação (SI) é muitas vezes do tipo top-down. Nesse caso, os aspectos dinâmicos do SI e atividades não são totalmente descritos. Essa abordagem tem um ponto de vista centrado no SI. A relação das atividades que cercam o SI é descrita como unificada. É possível descrever o fluxo de informação. A descrição de SI é contextualizada. A decomposição hierárquica é rejeitada como uma abordagem principal descritiva e analisada. Em vez disso, uma abordagem contextual é preferida. Diferentes contextos de atividades são descritos e ligados entre si (Goldkuhl, 1992). 
Ainda nesse contexto de políticas públicas, Carvalho, Barbosa e Soares (2010) explicam que na abordagem do tipo top-down a decisão política é autoritária, definida em um nível central. Por outro lado, a abordagem do tipo bottom-up leva em consideração a complexidade do processo de implementação. Observa-se que essas não são mutuamente excludentes, uma vez que ambas fornecem informação útil sobre o processo de implementação. Em alguns casos uma abordagem pode ser mais importante que a outra, e em outros casos ambas são igualmente relevantes, embora em diferentes fases do complexo e dinâmico processo de implementação.

Segundo Silva e Melo (2000), na visão clássica do ciclo de políticas públicas não se consideram os efeitos retroalimentares relativos à implementação sobre a formulação da política e esta nunca está a cargo de apenas um agente e não ocorre no âmbito de uma organização apenas, mas de um campo interorganizacional. Para os autores, a abordagem top-down centra-se na questão dos mecanismos de controle sobre os atores implementadores para que os objetivos da política sejam atingidos. Por sua vez, a abordagem bottom-up enfatiza os incentivos que induzem os atores implementadores a aderir normativa e operacionalmente aos objetivos da política. O ciclo de formulação e implementação de políticas públicas que consideram a retroalimentação e o monitoramento no processo já são vistos como um avanço à visão clássica.

Segundo Carvalho, Barbosa e Soares (2010), na implementação de novas políticas públicas é de suma importância que os gestores e profissionais tenham conhecimento e compreensão suficiente das variáveis do processo e do planejamento.

No ano de 2008 o governo federal alterou sua política institucional com a reforma da contabilidade governamental, instrumento de apoio às políticas públicas. A implementação do novo sistema de informação contábil foi baseada no modelo internacional da Ifac e deve ser adotado por todos os entes públicos da federação, União, estados e municípios.

\subsection{O processo de implementação do novo sistema de informação contábil na administração pública}

Qualquer processo de mudança na sociedade informacional envolve aspectos tecnológicos, estruturais e, em especial, relacionados à cultura e à geração do conhecimento, uma vez que é fundamental o envolvimento das pessoas participantes nesse processo (Amorim e Tomaél, 2011). O processo de implementação do novo sistema de informação contábil patrimonial baseado no modelo internacional não foi diferente, gerando impactos em diversos países do mundo (Zeff, 2007; Chan, 2010; Herbest, 2010).

A internacionalização da contabilidade aplicada ao setor público iniciou-se com a Ifac em 1977, com o propósito de fortalecer mundialmente a contabilidade do setor público. No Brasil, as International Public Sector Accounting Standards (Ipsas), conhecidas por Normas Internacionais de Contabilidade para o Setor Público (NICSP), são padrões internacionais de alta qualidade criadas para melhorar a elaboração de demonstrações contábeis pelo setor 
público, em que estes estabelecem regras de reconhecimento, mensuração, apresentação e evidenciação alistadas a transações e eventos em demonstrações contábeis para fins gerais (Zeff, 2007).

Segundo Chan (2010), o processo de elaboração das NICSP evoluiu em duas fases. De 1996 a 2002, o comitê da Ifac para o setor público (Ipsasb), essencialmente, importou normas contábeis e de relatório financeiro do setor privado para o setor público, fazendo alterações relativamente pequenas. A partir de 2003, o Comitê das NICSPs tem focado questões que são próprias do setor público, como tributos e orçamento para os relatórios financeiros.

O CFC, como órgão de classe, divulgou em 2008 as NBC T 16 (Normas Brasileiras de Contabilidades Aplicadas ao Setor Público), um conjunto de 10 normas, atualmente 11 após a publicação da NBCT 16.11 em dezembro de 2011. Fato inédito desde que o sistema CFC foi organizado há mais de 60 anos (Fragoso et al., 2012).

Segundo estudo de Fragoso e colaboradores (2012), a análise do estágio de convergência conceitual entre as normas brasileiras de contabilidade aplicadas ao setor público (NBCTSP) e as Ipsas demonstra que, por ordem de convergência avaliada, os tópicos referentes à NBC T 16.3 — planejamento e seus instrumentos sob o enfoque contábil e NBC T 16.7 - consolidação das demonstrações contábeis foram as normas que mais convergiram com os Ipsas, apresentando um percentual de aderência de 73,40\% e 71,43\% respectivamente. As normas que apresentaram um percentual de aderência abaixo de $10 \%$ de sua base conceitual foram: NBC T 16.4 - transações no setor público, NBC T 16.5 - registro contábil e NBC T 16.8 - controle interno. Os autores inferiram que as normas que mais convergiram mantêm em seu arcabouço conceitos mais atrelados à atualidade global, no que tange ao planejamento e ao processo de consolidação de demonstrações. Já no que se refere a transações no setor público, registro contábil e controle interno, predominam as características próprias (cultura, regulação, economia), o que pode justificar o pequeno percentual de convergência.

Já o governo brasileiro, por meio do Ministério da Fazenda, possui como marco importante desse processo a Portaria STN no 136, de 6 de março de 2007, que criou o GTCON, que no início priorizou seus esforços na elaboração de um novo Plano de Contas para permitir a consolidação das contas públicas. Foram realizados diversos estudos e discussões com a participação de vários órgãos e entidades técnicas representativas da sociedade.

No contexto brasileiro, o processo de convergência das normas contábeis aos padrões internacionais atingiu tanto o setor privado, quanto o setor público. Segundo Fragoso e colaboradores (2012), ao contrário do setor privado, onde a informação contábil tem uma influência muito forte no mercado de capitais, podendo afetar o preço de ações, o valor das empresas, a remuneração de executivos. No setor público, a principal função da informação contábil é o controle: verificar se os gastos públicos estão de acordo com as peças orçamentárias, se as receitas previstas foram devidamente arrecadadas, as áreas que necessitam de priorização de investimentos.

Para Ribeiro Filho e colaboradores (2009), o caso brasileiro reflete vários aspectos internacionais, no que tange à gestão pública. No decorrer dos anos é possível identificar diversos problemas de difícil solução, como é o caso das demandas cada vez maiores por serviços 
públicos em contraposição com a escassez de recursos. Tais problemas têm gerado dificuldades de natureza administrativa e financeira, bem como a geração de déficits constantes que devem ser demonstrados pela contabilidade.

Porém, o sucesso da reforma na contabilidade governamental depende da capacidade de mobilizar o apoio dos líderes políticos, que ajustam o tom pela exigência de uma maior prestação de contas (accountability) e transparência. Sua determinação política encontrará uma melhor possibilidade de realização se for reforçada pelo apoio de ministros e altos funcionários, a fim de alterar a forma pela qual o governo opera. Devido à sua natureza técnica, $\mathrm{o}$ marketing das propostas de reforma para os políticos e para os gestores do topo da hierarquia torna-se uma tarefa desafiadora (Chan, 2010).

\section{Procedimentos metodológicos}

Este estudo possui como estratégia de pesquisa a abordagem qualitativa, conforme explicam e orientam Godoy (1995c) e Creswell (2007). Godoy (1995b) sustenta que as pesquisas qualitativas partem de questões ou interesses amplos e procuram obter informações descritivas que envolvam pessoas, lugares e processos.

Essa perspectiva metodológica aproxima o pesquisador do ambiente para compreender o fenômeno que está sendo investigado. No entanto, Castro (2006) orienta que o pesquisador se mantenha independente do processo para evitar viés ou juízo de valor. Para isso, optou-se pela pesquisa documental para compreender o processo investigado a partir da perspectiva dos participantes (Godoy, 1995b:63), mas indiretamente pelos documentos públicos disponibilizados pelos atores envolvidos no processo de convergência.

Dessa maneira, a análise de conteúdo passa a ser o instrumento para obter as informações para descrever o fenômeno observado a partir dos documentos. Godoy (1995c:67) considera que a análise de conteúdo pela pesquisa documental "(...) constitui-se numa valiosa técnica de abordagem de dados qualitativos, podendo ser também utilizada para complementar informações obtidas em outras fontes".

Assim, partindo de uma perspectiva metodológica exploratória e descritiva para responder o problema de pesquisa, o estudo foi realizado em duas etapas. Na primeira etapa foi realizado um levantamento de informações e referências textuais, utilizando a pesquisa bibliográfica e documental (documentos em papel e arquivos eletrônicos). Buscou-se por meio dessa estratégia de pesquisa compreender o processo de implementação do novo sistema de informação da contabilidade aplicada ao setor público, nas leis, decretos, normas internacionais emitidas pela Ifac, e no arcabouço normativo emitido pelo CFC e pela Secretaria do Tesouro Nacional (STN).

A segunda etapa trata de uma descrição do ambiente informacional, da identificação dos atores envolvidos no processo, que podem ser órgãos de execução, controle ou de classe, e do mapeamento do fluxo das informações do processo de convergência aos padrões interna- 
cionais de contabilidade do setor público da Ifac, sendo, no caso brasileiro, o GTCON constituído por vários atores para facilitar a convergência.

Dessa maneira, foram analisadas as portarias (Portarias STN no 136, de 6 de março de 2007; no 415, de 15 de julho de 2010; no 582, de 13 de outubro de 2010; e no 109, de 21 de fevereiro de 2011), Regimento Interno, calendários das reuniões e listas de participantes do GTCON.

Esse segundo levantamento buscou por meio da lista de participantes do GTCON disponibilizada no site da Secretaria do Tesouro Nacional apurar: primeiro, a representação de membros da União, estados e municípios nesse grupo de trabalho; e segundo, a representação de órgãos de execução e controle do governo bem como entidades particulares prestadoras de serviço na administração pública.

Por fim, para consecução dos objetivos deste estudo, utilizou-se a lista mais recente quando da elaboração desta pesquisa, datada de maio de 2012, para identificar os atores que participaram da reunião. Essa é uma maneira para capturar a representatividade dos participantes no processo.

\section{Análise qualitativa e identificação do modelo}

\subsection{Apresentação e análise do ambiente informacional}

A análise desta pesquisa identificou e definiu o mapeamento de implementação do novo sistema de informação da contabilidade aplicada ao setor público. A identificação do modelo de convergência é importante para que os atores envolvidos possam compreender o processo por meio de uma visão macro, e assim conseguir definir seu papel dentro desse contexto evitando potenciais conflitos e sobreposições de decisões.

O modelo identificado retrata ainda o ciclo de produção de conhecimento na área da contabilidade aplicada ao setor público, por meio do processo de implementação de novas políticas contábeis que podem sofrer restrições por limitações do sistema de informações. No ciclo da produção do conhecimento, o primeiro momento é o da seleção e coleta de dados que são organizados para dar sentido à informação. "Após se considerar a informação existente sobre determinado tema, é possível estruturar uma visão sobre dado conhecimento que, ao estabelecer relações com outros conhecimentos, poderá gerar novos dados" (Novaes, 2011), em outras palavras, novas informações e novas abordagens.

Nesse ciclo, encontra-se a fase de implementação que representa o processo por meio do qual os objetivos podem ser alterados e recursos mobilizados para atender e realizar esses objetivos. Pode até ser vista como um processo de alteração da política que se quer implementar. Se não planejada, ela pode levar ao fracasso de uma política (Carvalho, Barbosa e Soares, 2010). Por esse motivo é importante que o modelo de implementação do novo sistema de informação da contabilidade aplicada ao setor público seja entendido por todos os atores envolvidos no processo, para que o conhecimento possa chegar até a base do modelo. 
Entre os atores principais do modelo estão: a IFAC, o CFC, a STN e o GTCON. Este último representando os órgãos de execução e controle dos governos federal, estaduais e municipais, bem como entidades particulares prestadoras de serviço para a administração pública. Cada um dos atores é explicado a seguir no quadro 1.

\section{Quadro 1}

\section{Definição dos atores que compõem o modelo do novo sistema de informação da} contabilidade aplicada ao setor público

\begin{tabular}{|c|c|c|}
\hline Órgão & Descrição & Produto \\
\hline $\begin{array}{l}\text { International Federation } \\
\text { of Accountants (Ifac) }\end{array}$ & $\begin{array}{l}\text { Organização global para a profissão contábil. } \\
\text { Fundada em 1977, com missão de servir ao } \\
\text { interesse público e fortalecer a profissão contábil } \\
\text { ao redor do mundo. } \\
\text { Engloba mais de } 160 \text { entidades associadas em } \\
\text { aproximadamente } 125 \text { países, dentre eles o Brasil. }\end{array}$ & $\begin{array}{l}\text { Conjunto de normas profissionais } \\
\text { internacionais referentes a auditoria, } \\
\text { asseguração, ética, educação e normas para } \\
\text { a elaboração de demonstrações contábeis } \\
\text { para os setores público e privado. }\end{array}$ \\
\hline $\begin{array}{l}\text { International Public } \\
\text { Sector Accounting } \\
\text { Standards Board } \\
\text { (Ipsasb) }\end{array}$ & $\begin{array}{l}\text { É o Conselho, constituído pela Ifac, responsável por } \\
\text { desenvolver e emitir sob sua própria autoridade } \\
\text { Normas Internacionais de Contabilidade para o } \\
\text { Setor Público (Ipsass). }\end{array}$ & $\begin{array}{l}\text { Conjunto de } 31 \text { normas internacionais } \\
\text { (Ipsas ou NICSP), das quais no Brasil } \\
\text { apenas } 30 \text { foram traduzidas. }\end{array}$ \\
\hline $\begin{array}{l}\text { Conselho Federal de } \\
\text { Contabilidade (CFC) }\end{array}$ & $\begin{array}{l}\text { É o órgão de representação profissional da classe } \\
\text { contábil no Brasil. Como órgão regulador das } \\
\text { práticas contábeis e membro da Ifac, constituiu } \\
\text { o Grupo de Trabalho da Convergência no Setor } \\
\text { Público (GTCP), para cumprimento da agenda da } \\
\text { convergência. }\end{array}$ & $\begin{array}{l}\text { Conjunto de } 11 \text { normas brasileiras de } \\
\text { contabilidade aplicadas ao setor público } \\
\text { (NBCASP). NBCT } 16.1 \text { a } 16.11 \text {. } \\
\text { Possui ainda Interpretação Técnica (IT SP) e } \\
\text { o Comunicado Técnico (CT SP). }\end{array}$ \\
\hline $\begin{array}{l}\text { Secretaria do Tesouro } \\
\text { Nacional (STN) }\end{array}$ & $\begin{array}{l}\text { É o órgão central de Contabilidade da União. } \\
\text { Possui atribuição de administrar os sistemas de } \\
\text { programação financeira, de execução orçamentária } \\
\text { e de contabilidade pública. }\end{array}$ & $\begin{array}{l}\text { Possui três produtos referentes a esse } \\
\text { processo. O MCASP, as notas Técnicas (NT), } \\
\text { e as Orientações Técnicas (OT). }\end{array}$ \\
\hline $\begin{array}{l}\text { Grupo Técnico de } \\
\text { Padronização de } \\
\text { Procedimentos } \\
\text { Contábeis (GTCON) }\end{array}$ & $\begin{array}{l}\text { Grupo de caráter técnico e consultivo } \\
\text { representativo dos atores que compõem a } \\
\text { base do modelo do processo de convergência. } \\
\text { Representado por órgãos de execução e controle. }\end{array}$ & $\begin{array}{l}\text { Recomendações consignadas em atas, com } \\
\text { objetivo de reduzir divergências e duplicidades, } \\
\text { em benefício da transparência da gestão } \\
\text { contábil, da racionalização de custos nos entes } \\
\text { da Federação e do controle social. }\end{array}$ \\
\hline
\end{tabular}

Fonte: Elaborado pelos autores.

\subsection{International Public Sector Accounting Standards Board (Ipsasb)}

Nos esforços para realizar sua missão, a Ifac constituiu o Ipsasb, que é o conselho responsável por desenvolver e emitir as Normas Internacionais de Contabilidade para o Setor Público (Ipsas). O Ipsasb conta com um Grupo Consultivo, sem poder de voto, que é principalmente um fórum eletrônico, porém há reuniões regionais ou, caso necessário, uma reunião em plenário com todos os membros do Grupo Consultivo pode ser realizada (Ifac, 2010). 
As Ipsas, que adotam regime de competência, são baseadas nas Normas Internacionais de Contabilidade (IFRS), emitidas pelo International Accounting Standards Board (Iasb), que são adaptadas ao contexto do setor público quando conveniente (STN, 2012).

Os membros do Ipsasb são indicados pelo comitê de nomeação e nomeados pela Diretoria da Ifac. Além disso, um número limitado de observadores, provenientes de instituições com interesse nas demonstrações contábeis do setor público, é nomeado, porém sem direito a voto. O processo legal do Ipsasb é demonstrado na figura 2.

Figura 2

Due process do Ipsasb

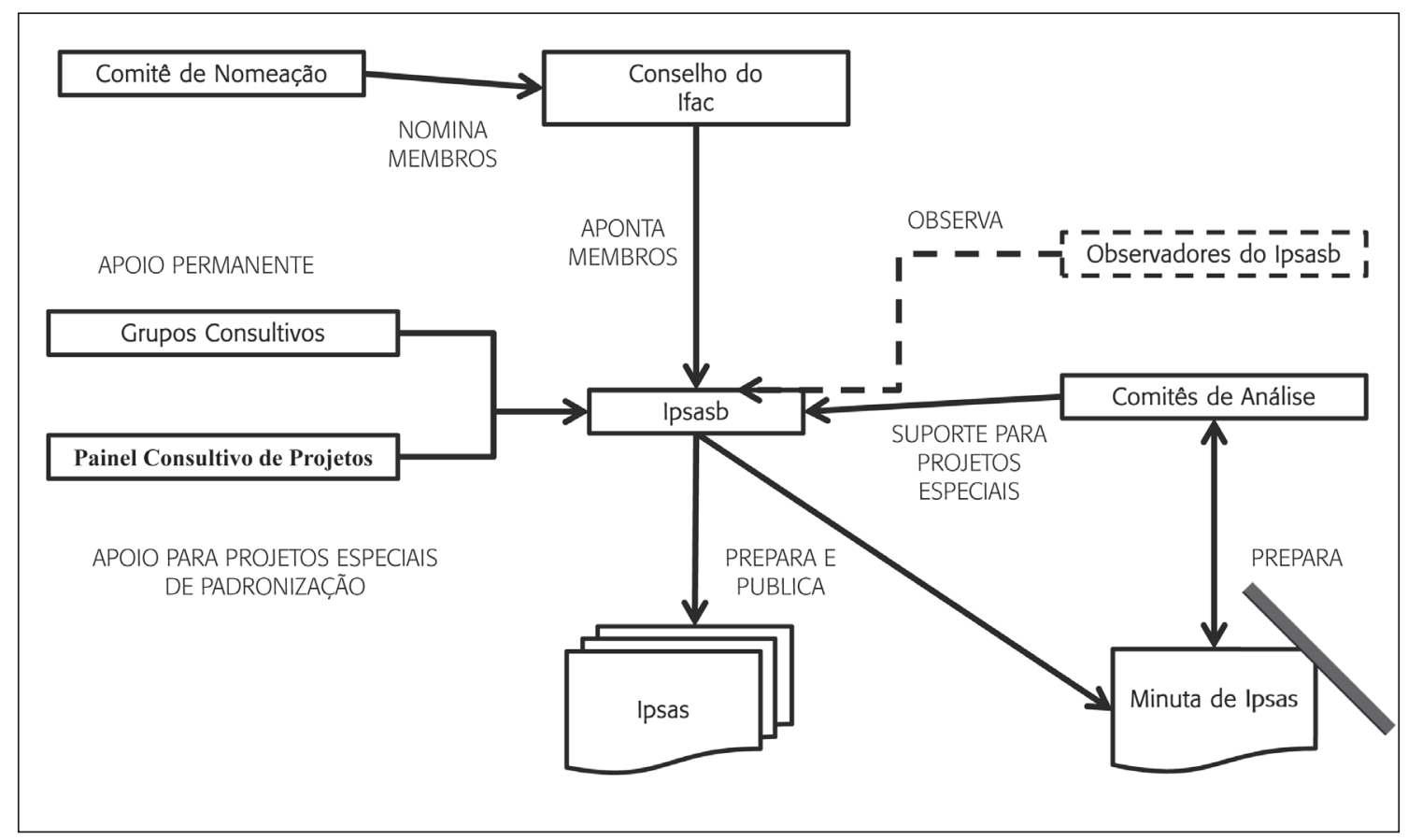

Fonte: STN (2012).

Para o desenvolvimento das Ipsass, o Ipsasb adota um devido processo legal que oferece oportunidade às partes interessadas apresentarem seus comentários, e inclui consulta ao seu Grupo Consultivo.

O devido processo legal do Ipsasb abrange os seguintes passos: 1. Estudo das normas e troca de diferentes pontos de vista sobre as questões discutidas com reguladores nacionais; 2. Consideração de pronunciamentos emitidos por: Iasb; Normatizadores em âmbito nacional, autoridades reguladoras e outros órgãos competentes; 3. Formação de comissões de coordenação e análise, comitês assessores do projeto ou subcomitês para providenciar dados sobre o projeto ao Ipsasb; 4. Publicação de uma Minuta Expositiva destinada à discussão e consulta 
pública; 5. Consideração de todos os comentários recebidos dentro do período de consulta pública; e 6. Publicação de uma Ipsas que inclui uma Base para Conclusões que explica os passos seguidos no devido processo legal do Ipsasb (Ifac, 2010).

\section{Grupo Técnico de Padronização de Procedimentos Contábeis (GTCON)}

No Brasil, o processo de convergência contábil no setor público foi desenvolvido pensando na participação de vários atores do processo, sejam órgãos de execução, controle ou particulares. Para isso, foi criado o GTCON, que é um grupo de caráter técnico e consultivo, manifestandose através de recomendações consignadas em atas, com objetivo de reduzir divergências e duplicidades, em benefício da transparência da gestão contábil, da racionalização de custos nos entes da Federação e do controle social (Portaria STN no 109/2011). É composto por representantes de todos os entes da federação, União, estados e municípios, entre órgãos de execução, controle e particulares. Assim, por meio desse grupo, os atores que compõem a base do modelo ganharam participação na construção do processo de convergência.

O processo é, desde o início, conduzido de maneira transparente pela Secretaria do Tesouro Nacional. Toda informação, incluindo lista de participantes, material de discussão, calendário e local das reuniões, está disponível no site da STN. As reuniões são realizadas de duas a três vezes no ano. Segundo a portaria STN nํ109/2011, o pleno do GTCON é composto por representantes vinculados às instituições apresentadas no quadro 2 .

$$
\text { Quadro } 2
$$

\section{Representação de Instituições de formação do GTCON}

\begin{tabular}{|lc|}
\hline \multicolumn{1}{|c|}{ Instituiçães de formação do GTCON } & Entes Federativos \\
\hline I. Secretaria do Tesouro Nacional (STN) & União \\
II. Associação Brasileira das Secretarias de Finanças das Capitais (Abrasf) & Município \\
III. Associação Brasileira dos Municípios (ABM) & Município \\
IV. Associação dos Membros dos Tribunais de Contas do Brasil (Atricon) & Estado/Município \\
V. Confederação Nacional dos Municípios (CNM) & Município \\
VI. Conselho Federal de Contabilidade (CFC) & União \\
VII. Conselho Nacional dos Órgãos de Controle Interno dos Estados e do DF (Conaci) & Estado \\
VIII. Consultoria de Orçamento e Fisc. Financeira, da Câm. dos Deputados (Conof) & União \\
IX. Consultoria de Orçamentos, Fiscalização e Controle, do Senado Federal (Conorf) & União \\
X. Controladoria-Geral da União (CGU) & União \\
XI. Departamento dos Regimes de Previdência no Serviço Público (DRPSP/SPS/MPS) \\
XII. Frente Nacional de Prefeitos (FNP) & União \\
XIII. Grupo dos Gestores de Finanças Estaduais (Gefin) & Município \\
\hline
\end{tabular}




\begin{tabular}{|lc|}
\hline \multicolumn{1}{|c|}{ Instituições de formação do GTCON } & Entes Federativos \\
\hline XIV. Instituto Brasileiro de Geografia e Estatística (IBGE) & União \\
XV. Instituto Rui Barbosa (IRB) & Estado/Município \\
XVI. Secretaria de Orçamento Federal (SOF) & União \\
XVII. Tribunal de Contas da União (TCU) & União \\
\hline
\end{tabular}

Fonte: Adaptado de STN (2012).

\subsection{Análise dos modelos}

O primeiro modelo de sistema de informação do setor público analisado nos dispositivos legais e normas contábeis foi o elaborado pela STN, conforme pode ser observado na figura 3.

\section{Figura 3}

Modelo de implementação do novo sistema de informação contábil no setor público

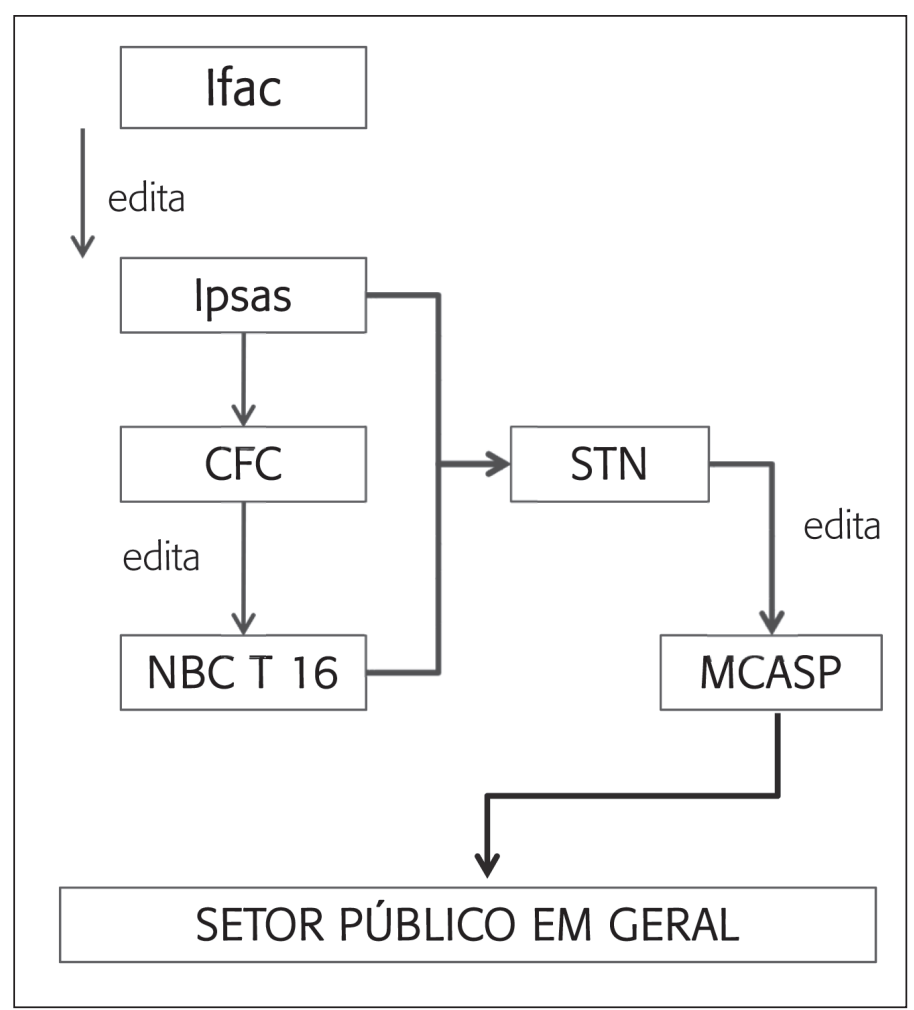

Fonte: Adaptado da Secretaria do Tesouro Nacional (2010). 
O modelo desenvolvido pela STN apresenta um processo simples, mas que não condiz com a real implementação da convergência contábil no setor público brasileiro, já que não leva em consideração a atuação do GTCON. No modelo da STN: i) a Ifac emite as normas internacionais (Ipsas); ii) o CFC estuda, discute e elabora as normas brasileiras, NBCASP ou NBCT 16, baseadas nas normas internacionais; iii) a STN edita os Manuais de Contabilidade Aplicada ao Setor Público (MCASP), com base nas normas brasileiras e internacionais; iv) os produtos desenvolvidos pelo CFC e STN são disponibilizados para o setor público em geral.

Entretanto, ao analisar o processo do modelo da figura 3, foram identificadas divergências entre o modelo exposto e o que ocorre na prática por meio da documentação analisada. Assim, foi possível apresentar um modelo alternativo, mais detalhado, considerando as abordagens top-down ou bottom-up.

Na análise dos modelos de implementação do novo sistema de informação da contabilidade aplicada ao setor público, percebe-se que a STN apresentou um modelo sem considerar um ator fundamental no processo, o GTCON.

Dessa forma, a abordagem top-down, no modelo da figura 3, parece prevalecer no processo de convergência das normas contábeis aplicadas ao setor público. Porém, a base do modelo formada pelo setor público possui representantes com direito a voto no GTCON, que contribuem na construção dos produtos (manual de contabilidade pública, normas técnicas, interpretações técnicas e orientações técnicas) que posteriormente serão implementados por eles mesmos.

Assim, não foi possível observar que a abordagem top-down tenha sido adotada na sua completude nesse processo, já que existe participação efetiva dos atores da base na construção das novas normas contábeis. Além disso, o modelo também não apresenta a participação da STN no CFC no processo de criação das novas normas contábeis. Pode-se afirmar que a participação do GTCON muda fundamentalmente a abordagem de implementação do novo Sistema de Informação Contábil no Setor Público.

Para a definição de um novo modelo, mais detalhado, foi realizado um levantamento no sítio eletrônico da STN, relacionando os documentos referentes à constituição e à realização do trabalho do GTCON. A análise foi realizada em duas etapas. A primeira etapa visando apurar a representação de membros da União, estados e municípios. A segunda etapa visando apurar a representação de órgãos de execução e controle do governo bem como entidades particulares prestadoras de serviço na administração pública.

Verificou-se que o grupo é formado por 22 membros titulares e 11 suplentes das instituições apresentadas no quadro 1 , dos quais apenas os membros titulares possuem direito a voto, na falta desses, os suplentes. O grupo é formado ainda por outros 119 membros participantes, que possuem direito de se manifestar com o intuito de colaborar com os debates, mas sem direito a voto.

Os resultados da primeira etapa mostram que, em relação à representatividade dos integrantes desse grupo, apurou-se, por meio da lista de participantes, que a maior participação é dos estados, seguida dos municípios, particulares (setor privado) e União. Já em relação à segunda etapa do levantamento, verificou-se que a maior participação é dos órgãos de execução, seguida dos órgãos de controle e entidades privadas. 
A tabela 1 apresenta a representatividade de cada ente da federação, bem como do setor privado e a representatividade de cada um desses órgãos e entidades nesse processo.

Tabela 1

Representatividade dos participantes do GTCON

\begin{tabular}{|c|c|c|c|c|c|}
\hline \multicolumn{3}{|c|}{$\begin{array}{c}\text { Painel A: Representatividade dos entes } \\
\text { integrantes do GTCON }\end{array}$} & \multicolumn{3}{|c|}{$\begin{array}{l}\text { Painel B: Representatividade dos órgãos } \\
\text { de controle e execução no GTCON }\end{array}$} \\
\hline Tipo de Ente Público & SDV & CDV & Tipo de Órgão Representante & SDV & CDV \\
\hline União & $3,3 \%$ & $30.3 \%$ & Total dos Participantes & 119 & 33 \\
\hline Estados & $45,0 \%$ & $27,3 \%$ & Controle & $22,5 \%$ & $57,5 \%$ \\
\hline Municípios & $37,5 \%$ & $18,2 \%$ & Execução & $63,3 \%$ & $42,5 \%$ \\
\hline Estados/Municípios & - & $24,2 \%$ & Privado & $14,2 \%$ & - \\
\hline Privado & $14,2 \%$ & - & TOTAL & $100 \%$ & $100 \%$ \\
\hline TOTAL & $100 \%$ & $100 \%$ & & & \\
\hline
\end{tabular}

Fonte: Elaborado pelos autores.

* CDV = Com Direito a Voto; SDV = Sem Direito a Voto.

Com isso foi identificado que existe representação e participação de todos os entes da federação que compõem a base do modelo de implementação do novo sistema de informação contábil do setor público brasileiro. Essa participação serve como retroalimentação do modelo, já que, à medida que os entes públicos implementam as novas políticas aprovadas, eles têm a oportunidade de apresentar suas limitações, dificuldades e também melhorias nas rotinas ocorridas na operacionalização dessas novas políticas contábeis.

Diante disso, após análise documental do material textual, o modelo adotado no Brasil para implementação do novo sistema de informação contábil no setor público pode ser representado como na figura 4.

Nota-se pela figura 4 uma mudança relevante do modelo identificado pela pesquisa documental, que possibilitou compreender o real fluxo do sistema de informação, distinto do modelo original apresentado pela STN na figura 3.

Diante disso, o modelo identificado não contempla totalmente a abordagem top-down, nem a bottom-up, mas sim a abordagem middle-up-down, que é intermediária e compartilhada. O modelo pode ser entendido por meio dos seguintes passos:

Primeiro, o Ipsasb (Conselho criado pela Ifac) emite as normas internacionais, que são traduzidas, no Brasil, pelo CFC em parceria com a STN, como órgãos reguladores da contabilidade aplicada ao setor público.

Segundo, a STN e o CFC interagem entre si. A STN participa das reuniões do grupo de convergência do setor público criado pelo CFC. E o CFC, por sua vez, participa do GTCON, que é um grupo técnico consultivo criado e coordenado pela STN, juntamente com representantes da União, estados e municípios. 
Figura 4

Modelo Identificado de implementação do novo sistema de informação contábil no setor público

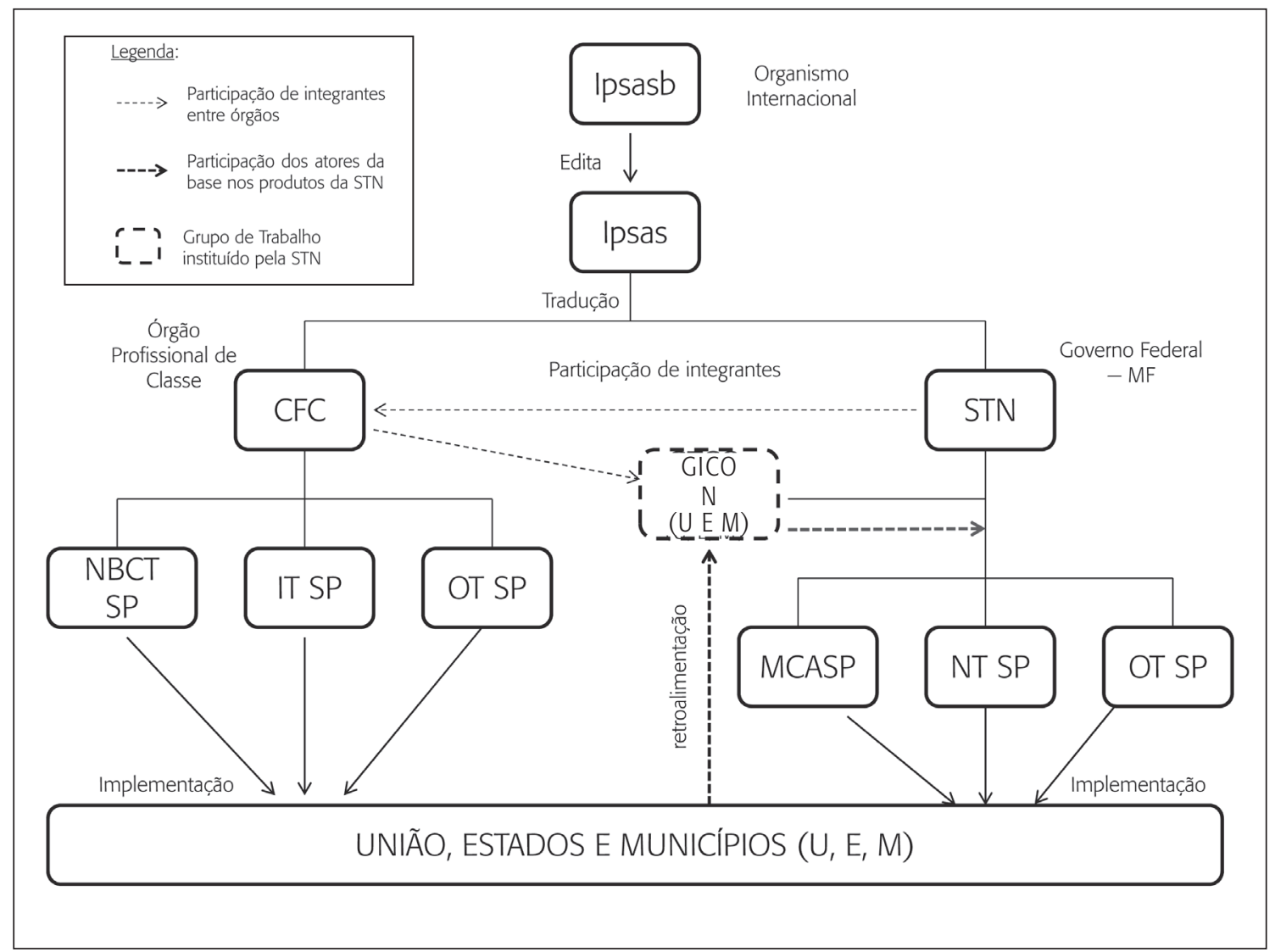

Fonte: Elaborado pelos autores.

Terceiro, o CFC e a STN emitem seus produtos que são direcionados aos atores, que por meio da geração de conhecimento implementarão as políticas contábeis definidas por esses órgãos, mas que também tiveram sua participação efetivada anteriormente por meio do GTCON, num processo de retroalimentação, em que esses membros (da União, estados e municípios) apresentam o contexto de suas realidades, desafios e oportunidades no processo de escolha das políticas contábeis que deverão ser implementadas por eles posteriormente.

Por fim, com base no modelo identificado, percebe-se que o modelo apresentado pela STN não considerou pontos essenciais do processo como: interligação entre o CFC e a STN em grupos de estudos; contribuição do GTCON como mediador da informação entre os atores da cúpula e da base do modelo; retroalimentação das informações discutidas no GTCON na elaboração dos novos produtos contábeis da STN. 


\section{Considerações finais}

A presente pesquisa, com abordagem qualitativa, identificou que o modelo de implementação do novo sistema de informação da contabilidade aplicada ao setor público é divergente do apresentado pela STN, com base nos documentos disponibilizados para consulta. Além disso, investigou os atores envolvidos no processo, bem como a contribuição de cada um deles no modelo identificado.

A importância de apresentar o modelo identificado, que ocorre na prática, é que na fase de implementação é de suma importância que os gestores e profissionais tenham conhecimento e compreensão suficiente das variáveis que compõem o processo, bem como entendimento da estrutura, hierarquia, funcionamento e dinâmica do sistema de planejamento e implementação a fim de evitar possíveis falhas ou até mesmo o fracasso do processo.

A análise qualitativa pela pesquisa documental e análise de conteúdo mostra que a estratégia do governo federal foi, desde o princípio, a de adotar uma abordagem compartilhada com os atores participantes do processo de convergência que compõem a base do modelo, ou seja, todos os entes públicos podem participar do processo por meio de um grupo técnico de discussão (GTCON) que é conduzido pela STN de forma transparente, principalmente, após a criação do GTCON. Somente quase um ano depois da portaria de criação do GTCON, foi que o governo federal, por meio do Ministério da Fazenda, publicou a portaria no $184 / 2008$, que trata da convergência do Brasil às normas internacionais de contabilidade do setor público. Em outras palavras, a estratégia de participação de representantes de todos os entes da federação (União, estados e municípios) no processo já estava previamente definida.

As análises realizadas neste trabalho mostram que, apesar de o Brasil optar pela adoção de um modelo internacional, e se aproximar da abordagem top-down, essa abordagem não foi escolhida na sua completude para implementação do novo sistema de informação contábil da administração pública. Isso pode ser confirmado pela estratégia do governo federal em não impor novas mudanças no processo antes da discussão e aceitação por parte dos órgãos de execução e controle que implementarão as novas políticas. Também não adotou a abordagem bottom-up já que não foi realizado um mapeamento do contexto cultural e organizacional dos atores envolvidos na base do modelo, antes da decisão de implementá-lo. Esses atores é que irão operacionalizar as novas políticas adotadas no processo. Assim, a abordagem adotada está numa etapa intermediária denominada middle-up-down, quando o conhecimento é gerado do meio para cima e para baixo.

Acredita-se que a criação do grupo técnico (GTCON) com representantes de todos os entes da federação com poder de voto nas decisões do governo em relação à implementação do novo sistema de informação contábil da administração pública foi um importante passo para que os atores envolvidos no processo pudessem ter participação efetiva na escolha das novas políticas contábeis apresentadas pelos órgãos reguladores.

Deve-se ressaltar que, como todo modelo teórico, esse modelo também apresenta fragilidades, dentre as quais cabe destacar: i) Não existe um comitê específico no setor público criado para o desenvolvimento deste trabalho, como existe no setor privado o Comitê de 
Pronunciamentos Contábeis (CPC), ou seja, o processo por parte do CFC não possui representação legítima dos órgãos, nem entes públicos, somente representantes indicados a convite do próprio $\mathrm{CFC}$; ii) o setor público, ao propor a alteração da contabilidade governamental, não atendeu por completo ao princípio da legalidade, ao desconsiderar o fato da não alteração da Lei no 4.320/1964; iii) O CFC, no processo de implementação, não considerou divulgar à classe contábil que tem adotado um modelo transitório próprio e não a adoção total das Ipsass como previsto inicialmente na Portaria MF no 184/2008; e iv) na abordagem middle-up-down qualquer mudança nas normas implementadas ensejaria a volta ao grupo para rediscussão do processo novamente.

O cenário da convergência possui outras implicações práticas como as evidenciadas por Fragoso e colaboradores (2012), que mostraram a distância das Ipsas estudadas com as normas brasileiras de contabilidade pública transformadas em resoluções pelo CFC. Apesar da ligação entre os órgãos reguladores, STN e CFC, há independência entre eles, e o CFC optou por adotar as Ipsas parcialmente, iniciando o processo com um regime próprio brasileiro.

Por fim, pode-se considerar que o processo de convergência das normas contábeis brasileiras às internacionais ainda irá percorrer um longo caminho até que todo o processo de implementação do novo sistema de informação contábil no setor público esteja completo. Essas evidências sugerem que novas políticas de disseminação do sistema sejam adotadas pelo governo para que a convergência seja de fato concluída.

Para futuras pesquisas, sugere-se analisar as consequências das normas em vigor e adaptadas, compreender as restrições à aplicação pelos contadores públicos e investigar conflitos de interesses na elaboração dos números contábeis.

\section{Referências}

ALLES, Michael G.; KOGAN, Alexander; VASARHELYI, Miklos A. Exploiting comparative advantage: a paradigm for value added research in accounting information systems. International Journal of Accounting Information Systems, v. 9, n. 4, p. 202-215, 2008.

ALVARENGA NETO, Rivadávia C. D.; BARBOSA, Ricardo R.; PEREIRA, Heitor J. Gestão do conhecimento ou gestão de organizações da era do conhecimento? Um ensaio teórico-prático a partir de intervenções na realidade brasileira. Perspectivas em Ciência da Informação, Belo Horizonte, v. 12, n. 1, p. 5-24, jan./abr. 2007.

AMORIM, Fabiana B.; TOMAÉL, Maria I. O uso de sistemas de informação e seus reflexos na cultura organizacional e no compartilhamento de informações. Perspectivas em Gestão \& Conhecimento, João Pessoa, v. 1, n. 1, p. 74-91, jan./jun. 2011.

BRITO, Lydia Maria P. Gestão do conhecimento — instrumento de apropriação pelo capital do saber do trabalhador. Cadernos de Educação, n. 30, p. 135-148, jan./jun. 2008. Disponível em: <www. periodicos.ufpel.edu.br/ojs2/index.php/caduc/article/viewFile/1748/1628>. 
CAPURRO, Rafael; HJORLAND, Birger. O conceito de informação. Perspectivas em Ciência da Informação, Belo Horizonte, v. 12, n. 1, p. 148-207, abr. 2007.

CARVALHO, Maria L.; BARBOSA, Telma R. C. G.; SOARES, Jeferson B. Implementação de política pública: uma abordagem teórica e crítica. In: COLOQUIO INTERNACIONAL SOBRE GESTIÓN UNIVERSITARIA EN AMÉRICA DEL SUR, X, 2010, Mar del Plata, Disponível em: <www.inpeau.ufsc. br/wp/wp-content/BD_documentos/coloquio10/214.pdf>. Acesso em: 14 abr. 2012.

CASTRO, Claudio de M. A prática da pesquisa. 2. ed. São Paulo: Pearson Prentice Hall, 2006.

CFC. Conselho Federal de Contabilidade. Altera, inclui e exclui itens das NBC T 16.1, 16.2 e 16.6 que tratam das Normas Brasileiras de Contabilidade Técnicas aplicadas ao Setor Público e dá outras providências. Resolução n. 1.268. Brasília, 2009.

CFC. Conselho Federal de Contabilidade. Conceituação, objeto e campo de aplicação, NBC T 16.1. Brasília, 2008a.

CFC. Conselho Federal de Contabilidade. Patrimônio e sistemas contábeis. NBC T 16.2. Brasília, 2008b.

CHAN, James L. As NICSPS e a contabilidade governamental de países em desenvolvimento. Revista de Educação e Pesquisa em Contabilidade, v. 4, n. 1, p. 1-17, jan/abr. 2010.

CRESWELL, John W. Projeto de pesquisa: métodos qualitativo, quantitativo e misto. 2. ed. Porto Alegre: Artes Médicas, 2007.

ESCRIVÃO, Giovana; NAGANO, Marcelo S.; ESCRIVÃO FILHO, Edmundo. A gestão do conhecimento na educação ambiental. Perspectivas em Ciência da Informação, v. 16, n. 1, p. 92-110, jan./ mar. 2011.

FALKENBERG, Edward D. et al. Frisco - a framework of information system concepts. Report of the IFIP WG8.1. Task Group FRISCO. 1998. Disponível em: <ftp://ftp.leidenuniv.nl/pub/rul/frifull.zip>. Acesso em: 24 abr. 2012.

FERREIRA, Aldónio; OTLEY, David. The design and use of performance management system: an extended framework for analysis. Management Accounting Research, v. 20, n. 4, p. 263-282, dez. 2009.

FRAGOSO, Adriana R. et al. Normas brasileiras e internacionais de contabilidade aplicadas ao setor público e o desafio da convergência: uma análise comparativa Ipsas e NBCTSP. REPeC, v. 6, n. 4, p. 434-447, out./dez. 2012.

GODOY, Arilda S. A pesquisa qualitativa e sua utilização em administração de empresas. Revista de Administração de Empresas, São Paulo, v. 35, n. 4, p. 65-71, jul./ago. 1995c.

GODOY, Arilda S. Introdução à pesquisa qualitativa e suas possibilidades. Revista de Administração de Empresas, São Paulo, v. 35, n. 2, p. 57-63, mar./abr. 1995b.

GODOY, Arilda S. Pesquisa qualitativa: tipos fundamentais. RAE - Revista de Administração de Empresas, São Paulo, v. 35, n. 3, p. 30-36, jan./fev. 1995a.

GOLDKUHL, Goran. Contextual activity modelling of information systems. In: PROCEEDINGS OF 
"3RD INT. WORKING CONFERENCE ON DYNAMIC MODELLING OF INFORMATION SYSTEMS", jun. 9-10, 1992, Noordwijkerhout.

HAGEDORN, Kat. The information architecture glossary. Argus Associates, mar. 2000. Disponível em: <http://argus-acia.com/white_papers/ia_glossary.pdf>. Acesso em: 12 abr. 2012.

HERBEST, Fabrício G. Regime de competência no setor público: a experiência de implementação de diversos países. In: ASSOCIAÇÃO NACIONAL DOS PROGRAMAS DE PÓS-GRADUAÇÃO EM CIÊNCIAS CONTÁBEIS (ANPCONT), 4., 2010, Natal (RN). Anais... Natal: ANPCONT, 2010.

HIRSCHHEIM, Rudy. A. Information systems epistemology: an historical perspective. Research methods in information systems. Amsterdã: North-Holland, 1992. p. 13-35.

HUFF, Anne. S. Designing research for publication. California: Sage, 2009.

IFAC. International Federation of Accountants. Handbook of international public sector accounting pronouncements. 2012. Disponível em: <www.ifac.org>. Acesso em: 24 abr. 2012.

IFAC. Internacional Federation of Accountants. Terms of reference. 2010. Disponível em: <www. ifac.org/public-sector/about-ipsasb/terms-reference>. Acesso em: 28 maio 2013.

IFIP. WG 8.1. E. D. Falkenberg, W. Hesse, P. Lindgreen, B. E. Nilsson, J. L. H. Oei, C. Rolland, R. K. Stamper, F. J. M. Van Assche, A. A. Verrijn-Stuart, K. Voss: FRISCO - A Framework of Information System Concepts. Report of the IFIP WG8.1. Task Group FRISCO. 1998. Disponível em: <ftp://ftp. leidenuniv.nl/pub/rul/fri-full.zip>.

LIMA, Luciana L.; D’ASCENZI, Luciano. Implementação de políticas públicas: perspectivas analíticas. In: ENCONTRO NACIONAL DE PESQUISADOS E GESTÃO SOCIAL-ENAPEGS, VI, 2012, São Paulo.

LOPES, Jorge E. G. et al. Um estudo sobre a complementaridade do fluxo de caixa e do balanço financeiro após a aprovação da NBCASP 16.6 para o setor público. In: ASSOCIAÇÃO NACIONAL DOS PROGRAMAS DE PÓS-GRADUAÇÃO EM CIÊNCIAS CONTÁBEIS (ANPCONT), 4., 2010, Natal (RN). Anais... Natal: ANPCONT, 2010.

MORAES, Marcelo B.; NAGANO, Marcelo S. Sistemas de informação contábeis: uma abordagem orientada a objetos com agentes inteligentes. Journal of Information Systems and Technology Management, v. 6, n. 3, p. 463-482, 2009. Disponível em <www.revistasusp.sibi.usp.br/scielo. php?pid=S1807-17752009000300005\&script=sci_arttext $>$. Acesso em: 25 jun. 2013.

NASCIMENTO, Leonardo S. do. A reforma da contabilidade governamental brasileira: a necessária revisão dos preceitos vigentes em face das demandas de informações e do esforço de harmonização nacional e internacional. Brasília: Esaf, 2007. (Monografia premiada com o terceiro lugar no XII Prêmio Tesouro Nacional — 2007. Tributação, Orçamento e Sistemas de Informação sobre Administração Financeira Pública. Florianópolis, SC)

NONAKA, Ikujiro. Toward middle-up-down management: accelerating information creation. Sloan Management Review, v. 29, n. 3, p. 9-18, Spring 1988.

NONAKA, Ikujiro; TAKEUCHI, Hirotaka. Criação de conhecimento na empresa. Rio de Janeiro: Elsevier, 1997. 
NOVAES, Denise. Reflexões linguísticas para a organização hierárquica de conceitos em tesauros. In: DUQUE, Cláudio G. (Org.). Ciência da informação: estudos e práticas. Brasília: Thesaurus, 2011. p. $95-150$.

OLIVEIRA, José Antônio. P. Desafios do planejamento em políticas públicas: diferentes visões e práticas. Rev. Adm. Pública, v. 40, n. 1, p. 273-288, mar./abr. 2006.

PEREIRA, Heitor J. Bases conceituais de um modelo de gestão para organizações baseadas no conhecimento. 2003. Disponível em: <www.inei.org.br/inovateca/artigos-sobre-empreendedorismo-einovacao >. Acesso em: 13 abr. 2012.

RIBEIRO FILHO, José F. et al. Evolução da contabilidade financeira na perspectiva emancipatória de Erich Fromm: O processo de construção das Normas Brasileiras de Contabilidade Aplicadas ao Setor Público - NBCASP. Sociedade, Contabilidade e Gestão, v. 4, n. 1, p. 5-20, jan./jun. 2009.

RODRIGUES FILHO, José; LUDMER, Gilson. Sistema de informação: Que ciência é essa? Revista de Gestão da Tecnologia e Sistemas de Informação, v. 2, n. 2, p. 151-166, 2005.

SILVA, Arídio; RIBEIRO, José A.; RODRIGUES, Luis. A. Sistemas de informação na administração pública. 1. ed., 1. reimp. Rio de Janeiro: Revan, 2004.

SILVA, Pedro Luis B.; MELO, Marcos André B. O processo de implementação de políticas públicas no Brasil: características e determinantes da avaliação de programas e projetos. Campinas: Universidade Estadual de Campinas, Núcleo de Estudos de Políticas Públicas (Nepp), 2000. (Caderno n. 48)

SÖTHE, Ari; SCARPIN, Jorge Eduardo. Estudo n 14 do Ifac: impactos na implementação do regime de competência no governo municipal de Iporã do Oeste - SC. In: CONGRESSO USP DE CONTROLADORIA E CONTABILIDADE, 10., 2010, São Paulo. Anais... Natal: Anpcont, 2010.

STN. Secretaria do Tesouro Nacional. Contabilidade Pública — Padronização de Procedimentos — Grupo Técnico. Portaria STN n 415. Brasília, 2010.

STN. Secretaria do Tesouro Nacional. Módulo XIII: introdução às normas nacionais e internacionais de contabilidade aplicadas ao setor público. Brasília: 2012. Disponível em: <www3.tesouro. gov.br/contabilidade_governamental/treinamentos_eventos_ccont_novosite.asp >. Acesso em: 28 maio 2013.

STN. Secretaria do Tesouro Nacional. Portaria STN nº 37. Brasília, 2004.

STN. Secretaria do Tesouro Nacional. Portaria STN n 109. Brasília, 2011.

STN. Secretaria do Tesouro Nacional. Portaria STN nº 136. Brasília, 2007.

STN. Secretaria do Tesouro Nacional. Portaria STN no 582. Brasília, 2010.

XAVIER JÚNIOR, Antônio E.; PAULO, Edilson; SILVA, José Dionísio G. Estudo sobre a capacidade informacional das novas estruturas das demonstrações contábeis aplicadas ao setor público. In: ASSOCIAÇÃO NACIONAL DOS PROGRAMAS DE PÓS-GRADUAÇÃO EM CIÊNCIAS CONTÁBEIS (ANPCONT), 4., 2010, Natal (RN). Anais... Natal: ANPCONT, 2010. 
ZEFF, Stephen A. Some obstacles to global financial reporting comparability and convergence at a high level of quality. British Accounting Review, v. 39, n. 4, p. 290-302, 2007. Disponível em: <www. ruf.rice.edu/ sazeff/PDF/Some\%20Obstacles.pdf>. Acesso em: 20 jun. 2013.

ZINS, C. Conceptions of information science. Journal of the American Society for Information Science and Technology, v. 58, n. 3, p. 335-350, 2007. Disponível em: <www.success.co.il/is/zins_conceptsof_is.pdf>. Acesso em: 6 dez. 2011.

ZINS, C. Knowledge map of information science. Journal of the American Society for Information Science and Technology, v. 58, n. 4, p. 526-535, 2007a.

Janyluce Rezende Gama é doutoranda em ciência da informação. Mestre em contabilidade gerencial pela Fucape. Professora assistente do Departamento de Ciências Contábeis da Ufes. E-mail: janylucegama@ gmail.com.

Claudio Gottschalg Duque é doutor pelo Programa de Pós-Graduação em Ciência da Informação pela Escola de Ciência da Informação. Professor adjunto do Departamento de Ciência da Informação e Documentação da Universidade de Brasília (CID-UnB) e coordenador do DInter UNB/Ufes. E-mail: klaussherzog@gmail.com.

José Elias Feres de Almeida é doutor em controladoria e contabilidade pela Universidade de São Paulo (FEA/USP). Professor adjunto do Departamento de Ciências Contábeis e dos Programas de Mestrado em Ciências Contábeis e Gestão Pública da Ufes. E-mail: jose.elias.almeida@gmail.com. 